\title{
Context of abuse against men: Perspectives on causes, consequences and coping mechanisms
}

\author{
Oladele Opeyemi Aboderin ${ }^{1}$, Ademuson, A. $0^{1}$, Adegoke, $0.0^{1} \&$ Olayinka \\ Akanle ${ }^{1},{ }^{2}$ \\ ${ }^{1}$ Department of Sociology, University of Ibadan, Nigeria \\ ${ }^{2}$ University of Johannesburg, South Africa \\ Email: yakanle@yahoo.com
}

\begin{abstract}
Background: Opinions on gender abuse have been largely skewed towards females. However, the rising number of cases of abuses against the male gender has brought the need to seek better understanding on the different background contexts and conditions surrounding the abuses against men in Nigeria.

Data Source and Methods: This article was based on a cross-sectional study on abuse against men through quantitative and qualitative methods. It examined perspectives on causes, consequences and coping mechanisms relative to abuse against men in urban Ibadan, Oyo State, Nigeria.

Results: Findings suggest that various forces at individual, familial, cultural, urbanization, westernization and globalization levels drive abuse against men and men cope with the abuse through avoidance, divorce, resignation, adjustment and religion.

Conclusion: Findings suggest that various forces at individual, familial, cultural, urbanization, westernization and globalization levels drive abuse against men and men cope with the abuse through avoidance, divorce, resignation, adjustment and religion.
\end{abstract}

Keywords: Abuse against Men, Causes and consequences of Abuse against Men, Coping Mechanisms of Abuse Men in Urban Ibadan.

\section{Introduction}

Societies, especially patriarchal societies, have often relied on the narrative that men are the dominant and stronger party in social relationships. This can be seen in the ascription of roles and expectations that is placed on men as the heads of family as well as the kinds of duties they perform. This is especially true of most African societies, where men are traditionally recognized as the stronger party in almost all circumstances (Ayodele, 2017). Men are believed to be more powerful than women, and are seen to be better equipped to take on difficult tasks and functions. This was also reflected in the primordial society where men were the Hunters who could face and overpower deadly and wild animals, while women were restricted to the perceived less harmful role as Gatherers. According to Morgan \& Wells (2016), men have been socialized to exercise control over women through social, institutional and cultural norms in the society. Interestingly, the society has held on to this trend of assumption of male dominance, even as the society evolved into this contemporary time. Men are reputed to be formidable and can always protect themselves in African societies, which is mostly patriarchal (Namadi, 2017; Obarisiagbon and Omage, 2019).
Hence, it is usually assumed that men always have the upper hand in social relationships, such that they cannot be abused. This opinion is corroborated by Namadi (2017) who noted that when issues of domestic abuse or violence are discussed in the society, women and children are presumed to be the default victims. This is because women have often been seen and treated as belonging to the vulnerable group in the society, who needs to be protected from harm or danger.

Women are more focused as the vulnerable ones, while men are left to fight for their safety and wellbeing in the same society. An instance of this can be seen in the rape laws which is female centered (Adeniyi, 2018). Most rape cases are examined with women as the focus while ignoring the male victims. Also, gaining custody of children from an abusive mother is usually difficult for the man, as he is made to prove beyond reasonable doubts that such woman cannot take care or portends danger to such children (Adeyeri, 2013). In the same vein, most advocacies are centered on women as the victims of abuse in the society. Most governmental and non-governmental organizations whose mandate is to prevent abuse are focused on female abuse, thereby leaving men at the 
mercy of their abusers. The various advocacy and sensitization are more or less in favor of women victims, thereby leaving the male victims to suffer in silence. Caroletta (2010) also noted that due to the rise of various groups such as the feminist movements, women have been strongly recognized as the victim of violence and other forms of abuses. Hence, when women are found to carry out any of form of abuse, they are said to be doing so in selfdefense. This contributes to the discrimination of men who are victims of abuses carried out by women. Also, Drijber, Reijnders and Ceelen (2013) pointed that studies have shown that the abuse of women by men have been categorized as more negative than when women perpetrate abuse against men. This could be ascribed to the fact that female abuse has been found to be more common in the society, and thus have attracted more condemnation. It was noted that abuse against men has not gained much recognition and study attention as opposed to female abuse. Hence, abuse against men in the society often times goes unrecognized and underreported for necessary proactive actions to be taken.

The context of abuse against men can be said to be influenced by so many factors. These factors are issues that are peculiar to different environments, and which makes the perception and nature of abuse against men in one society vary from the context in another society. Various studies have pointed out that intimate partner violence is a critical global public health problem (Beydoun, 2012; Ellsberg, Henrica, Heise, Watts, \& García-Moreno, 2008; Randle \& Graham, 20II; Tjaden \& Thoennes, 2000; World Health Organization, 20/3). In spite of this, the conditions surrounding abuse against men cannot be said to be generic, and this is why each individual experience varies. Despite the notion of abusive experiences such as; physical violence, sexual violence, stalking and/or psychological aggression being female centered, this does not exclude men even when the definition is clearly silent over gender. The stigma keeps male victims away from disclosure, but does not imply the non-existence or foreclosure of the social problem (Ayodele, 2017). It is against this background that this article empirically examined and provided the causes and consequences of abuse against men as well as coping mechanisms adopted by men who are abused in Ibadan Urban, Nigeria.

\section{Ramifications of abuse against men}

The level of stigmatization faced by men who are abused is an indicator of the worldview of people about abuse against men in the society (Johnson, 20II). The stigma that follows the declaration of abuse on a man by a woman has shaped the way abuse against men is perceived among the people in the society (Ayodele, 2017). Abuse against men in the society has been seen as a taboo and as such many men would rather choose to be silent about their experiences, due to the way it is portrayed in the society. Ayodele (2017) noted that men who are abused are socially rejected and therefore this affects their confidence to speak out and seek help for their abuses. According to Caroletta (2010), issues of abuse in the society have been treated as a rather personal problem than social problem. This view is especially held if the abuse is not violent. Therefore, most individuals would rather keep quiet and deal with it themselves. However, recent happenings and emancipation of human rights have reviewed how abuse is taken in the society (Johnson, 2008, Kimmel, 2002). The idea that men do not experience abuse does not represent the reality in different societies, including Nigeria. It has been observed that many men face different forms of abuse from their partners in social relations. However, these men do not just have the gut to openly report or express their experiences because of shame, bearing the nature of the society (Krug, 2002). Most men who suffer abuse have rather adopted the silence approach in order to save their face in the society (Morgan and Wells, 2016).

While it has been noted that the context of abuse against men is a factor of so many things based on different environments, Dutton and White (20/3) showed that surveys in the United States and Canada, revealed that many female abusers have abusive familial backgrounds, or might have witnessed same while growing up. Ayodele (2017) pointed out that the socialization that an individual gets plays a role in his or her disposition towards abuse against men. The family being an agent of socialization, its role in the $s$ socialization cannot be overemphasized in the society. Most women are noted to develop and learn various behaviors from the home during the developmental phase. Therefore, women who are exposed to abusive behaviors during this growth phase also imbibe same to exhibit in their future relationships. An example of this was revealed in a study carried out by Ayodele (2017) where it was revealed by one of the abuse male participants that due to the experiences of his wife who had seen her mother assault her father to her admiration, she towed the same line.

While some women might not have learnt the abusive behaviors from their immediate families but from other interactions and associations with other individuals, it has also been noted that wrong counsels from these interactions have also 
contributed to some of the abuse men face. These instances abound in the society and have further created more problems for men. Therefore, the woman upon attaining adulthood also sees abuse as a part of ways of living, especially in order to enforce her personal goals. Abuse can be said to thrive more in solitary environments, where there are not too many people to interfere in the affairs of the man and woman (Morgan and Wells, 2016). This can be adduced as a reason why the level of prevalence has been observed to be lesser in African societies. This is due to the communal way of living, which is commonly adopted among most of the people. Principally, only close relatives get to know about the abuse and this usually is when the abuse leaves marks like scar or injury on the male victim. This only becomes public knowledge when the experience turns life-threatening or ultimately results in the death of the male victim. The silence and endurance coping mechanism which had been observed to be common among men are being largely attributed to the ridicule and guilt which male victims are subjected to. This had been noted to have psychological effect on men. Most abused men result to alcohol and drug abuse and many often become depressed from their silent sufferings.

Several mechanisms have been pointed out in studies as engaged by the male victims of abuse in order to cope with their predicaments (Dutton and White, 2013; Adebayo, 2014; Namadi, 2017; Ayodele, 2017). These coping strategies include both formal and informal ways which have been found to be commonly adopted by victims of abuse against men in the society. According to Ayodele (2017) the stigmatization that comes with the abuse of men in the society has influenced the methods of coping adopted by these male victims. Many feel embarrassed and ashamed of themselves, and as such would rather keep their experiences to themselves. The silence culture had been mostly adopted by most victims, as they would not like to be seen as a weakling (Obarisiagbon and Omage, 2019). This is further influenced by the masculine notion that men are supposed to be more powerful and stronger. Hence, a man who comes out to declare that he had been abused by a woman is subjected to ridicule and shame for not been man enough. Consequently, male victims of abuse in most cases, tend to handle their problems privately, so as to avoid social stigmatization from friends and close relationships. Conversely, in rare occasions, some males also victims rely on the help they get from their family and friends in the terms of emotional support and as a means of distraction from their problems, while looking for access to other coping resources that may be available. This article, therefore examined the worldviews and coping mechanisms of male victims of abuse as influenced by peculiar contexts of an urban African society.

\section{Theoretical framework}

Dollard, Doob, Miller, Mowrer, and Sears (1939)'s Frustration Aggression Theory proposes that the occurrence of aggressive behavior always presupposes the exhibition of frustration, which ultimately informs aggressive outcome or worldview. Different factors are however believed to be a major influence on frustration and aggression, among which are social and environment contexts of social relations. Breuer and Elson (2017), defined frustration as an event instead of an affective state. Hence, frustration can occur in the form of any activity or experience which is observable, and can result in disappointment or the unsuccessful achievement of one's goal. This can lead to different negative emotional and behavioral reactions, such as aggression. Essentially, the theory believes that when people are unable to reach their goals or expectations as the case maybe, they become frustrated and that could predispose them to unleashing aggressive behavioral outbursts. Hence, it can be said that the presence of frustration leads to some form of aggression (Obarisiagbon and Omage, 2019). Frustration and Aggression can be subject to the worldview and social contexts of individuals as reflected in the way social and intimate relationships are managed. Contexts of relationships inject certain expectations and roles on men and women, and these expectations are being redefined by the level of industrialization and westernization as seen in the society. Therefore, this explains how the urban peculiarities experienced by both men and women, could predispose the frustration of individuals and the development of aggressive behaviors, which amounts to abuse in the urban society and as well influence available coping mechanisms.

\section{Data and methods}

Ibadan is in Southwestern Nigeria. It is a cosmopolitan society with appreciable urbanization but a strategic blend of traditionalities. Ibadan is one of the most traditional yet modernizing societies in Africa and among the largest on the continent. The rich blend of traditionalities and modernity makes the choice of lbadan as context of this study relevant. Ibadan is the capital of Oyo State, Nigeria and it is continually described as the largest indigenous city in tropical Africa by Shittu, Onuegbu, Ayinmoro and Fayehun (2018). Ibadan haslI local government areas, with five of them classified as urban. This article which is based on the research conducted in the indigenous city selected five urban local 
governments namely; Ibadan North, Ibadan Northeast, Ibadan Northwest, Ibadan Southeast, and Ibadan Southwest for the study. The urban (there is also Ibadan rural but this study did not cover the rural Ibadan) which is characterized by different people who engage in different socio-economic activities, that spans across both the formal and informal sectors.

This can be ascribed to the increasing number of people who throng the urban center. Individuals' worldview are therefore shaped as they face different dilemmas in a bid to navigate the pressures of the urban center for survival. The study was a descriptive study which engaged both qualitative and quantitative methods using multistage sampling. Data were collected through qualitative methods from Interviewees purposively selected based on their experience, availability and personal memories of abuse against men. Twenty-five in-depth interviews were conducted with purposively selected men and women and 10 key informant interviews with purposively selected community and religious leaders as well as security agents in the purposively selected areas. Two Hundred and ten copies of questionnaires were administered on randomly selected respondents for the quantitative data. Data analysis was carried out using Statistical Package for Social Sciences (for the quantitative data) while content analysis and ethnographic categorizations were used to analyze qualitative data. Ethical considerations of informed consent, confidentiality, beneficence, non-maleficence and anonymity were strictly adhered to throughout the study.

\section{Results}

This section presents the results and findings from the fieldwork based on the data collected and analyzed from the fieldwork.

Socio-demographic characteristics of respondents The majority which constitute $69.5 \%$ of the respondents for the study were males, while $39.5 \%$ were females. This shows that the opinions of more males were sampled due to the nature of the study which was male-centered. Also, $78.6 \%$ of the respondents were between the ages of $21-40$, while the remaining $21.4 \%$ were aged $4 I-60$. This indicates that majority of the respondents for the study are young adults who constitute a sizeable number of urban dwellers. Moreover, a higher proportion which constitute $84.3 \%$ of the respondent were of the Christian faith, while the remaining $15.7 \%$ were of the Islamic faith. Furthermore, $24.3 \%$ of the respondents were single, $72.4 \%$ were married, $2.9 \%$ were either divorced or separated while only one of the respondents which represent $0.5 \%$ was a widow. In addition, the $74.8 \%$ of the respondents were Yoruba, $20.5 \%$ were Igbo, while $2.9 \%$ and $1.9 \%$ of the respondents were Hausa and Edo respectively. This shows that majority of the respondents were Yoruba, which is due to the study area being a popular urban center in the Southwestern part of Nigeria. Also, 94.3\% majority of the respondents had tertiary education, while the remaining $5.7 \%$ had primary education. Meanwhile, the employment status of the respondents revealed that $83.8 \%$ which constitute majority were employed, while $16.2 \%$ were unemployed.

\section{Worldview on abuse against men in urban lbadan} Majority of respondents (80\%) believe men are strong, while $20 \%$ of the respondents are of the opinion that men are not strong. This indicates that majority of the respondents still share the popular opinion that men have physical strength. Hence, one can deduce that men may not suffer as much physical abuse like women. This is because women are seen and treated as part of the weak and vulnerable members of the society. This conforms to the general view of most individuals in the society, and therefore makes it difficult for men to report their abuses. Also, a small proportion, (5.2\%), of the respondents believe that men are the cause of their own abuse, while a higher $94.8 \%$ of the respondents believe men are not the cause of their own abuse. This shows that majority of individuals are of the opinion that abuse against men is not largely influenced by the men themselves, but by other factors. It was also found that majority $(96.7 \%)$ of the respondents agreed that financial incapability contributed to the abuse against men, while the remaining $3.3 \%$ of the respondents disagreed.

Meanwhile, $85.7 \%$ which constitute majority of the respondents agreed that abuse against men lead to increase in female abuse, while $14.3 \%$ of the respondents disagreed that abuse against men lead to further increase in female abuse. From this, it can be pointed out that a large number of the respondents opined that the abuse of men can further instigate the abuse of women. This could arise as a way of retaliation, and also sometimes due to the nature of the society, which is mainly patriarchal, men might result in more abuse of women in a bid to further entrench their belief in male domination. Furthermore, $94.3 \%$ of the respondents were of the opinion that abused men should speak out, while $5.7 \%$ of the respondents were of the opinion that abused men should not speak out. It can be pointed out from this outcome that, due to the increasing 
cases of abuse against men in Nigeria, where many men keep their experiences to themselves and suffer in silence, many people now advocate for men who are abused to speak out in order to seek help.

The study further investigated the level of association between the different sociodemographic factors and abuse against men in Urban Ibadan. It was found that there is no significant association between religion and men being the cause of their abuse $\left(X^{2}=\right.$ I.I7I, $p>0.05)$. This shows that the religion of the participants is not associated with their perception of men as the cause of their own abuse in the study area. This is because majority of the participants from the different religions in the study area opined that men are not the cause of their abuse. There is a weak significant association between marital status and the perception of men being the cause of their abuse $\left(X^{2}\right.$ $=23.892, \mathrm{p}<0.05)$. This indicates that the participants' marital status is associated with their perception of men as the cause of the abuses they suffer. Even though majority of the participants disagreed that men are the cause of their abuse, only a participant with the minority marital status agreed that men are the cause of their abuse. This can be adduced as the reason for the weak association between the variables. Also, it was found that there is no significant association between educational status and the perception of civilization as a cause of abuse against men $\left(X^{2}=0.057, p>0.05\right)$. This implies that the educational status of participants is not associated with their perception of civilization as a cause of abuse against men. This is due to majority of the participants irrespective of their educational status, agreed that civilization had contributed to abuse against men in the study area.

Furthermore, there is a significant association between employment status and the view on female engagement in economic activity as a cause of abuse against men $\left(X^{2}=4.293, p<0.05\right)$. This is because a greater percentage of the employed participants believe female engagement in economic activity causes abuse against men. A little above average of the unemployed participants shared the same belief. There is no significant association between employment status and perception of polygamy as a cause of abuse against men $\left(X^{2}=1.195, p>0.05\right)$. This indicates that the employment status of the participants is not associated with their perception of polygamy as a cause of abuse against men in the study area, in as much as majority of the participants are of the opinion that polygamy causes abuse against men. In addition, there is no significant association between gender and the perception on men being the cause of their abuse $\left(X^{2}=1.229, p>0.05\right)$.

This indicates that the view on men being the cause of their own abuse is not associated with being male or female, as majority of the participants disagreed. Also, there is a significant association between gender and the perception of the strength of men in the study area $\left(X^{2}=4.293, p<0.05\right)$. This shows that the gender of the participants is associated with how they perceive the strength of men. This can be said to be influenced by the social and cultural depiction of the male gender in the study area. Lastly, there is no significant association between employment status and perception of financial incapability as a cause of abuse against men $\left(X^{2}=0.818, p>0.05\right)$. This alludes that the perception of the participants on financial incapability causing abuse against men in the study area is not associated with their employment status.

\section{Context of abuse against men in urban Ibadan}

Findings suggest that $91.9 \%$ majority of the respondents agreed that the environment plays a role in abuse against men, while the remaining $8.1 \%$ of the respondents disagreed that the environment plays a role in abuse against men. This means a large proportion of the respondents believe that the peculiar nature of each environment could contribute to the abuse against men. Also, $32.4 \%$ of the respondents are of the opinion that culture plays a role in the abuse against men, while $67.6 \%$ of the respondents are of the opinion that culture does not play a role in the abuse of men. This indicates that a higher percentage of the respondents believe that the way of life of a people does not contribute to abuse against men. This can be informed by what constitutes the normative form of behavior in the society. Since abuse is frowned at in the society, it is unlikely going to be influenced by the culture of the society. However, it should be pointed out that different sub-cultures among a particular group of individuals can contribute to abuse against men.

In addition, $88.6 \%$ of the respondents agreed that urbanization contributes to abuse against men, while $11.4 \%$ of the respondents disagreed that urbanization contributes to abuse against men. This reveals that a higher percentage of the respondents are of the opinion that urbanization plays a role in the abuse against men. Part of the indices of urbanization which includes overpopulation and industrialization, marks a significant difference in the way of life of the people. Hence, due to these features of urbanization, the abuse of men can be said to thrive. Furthermore, 93.3\% which constitutes majority of the respondents believe civilization contributes to abuse against men, while $6.7 \%$ of the respondents believe civilization does not contribute to abuse against men. This according to the respondents infers that cases of abuse against men were less rampant in the olden days. However, majority of the respondents opine 
westernization has brought along with it some other practices and experiences which were hitherto uncommon.

The context of the environment had been observed to influence the experience of abuse against men in Urban Ibadan. This is due to the nature of the urban town and its accompanying characteristics. It is believed that the solitary way of life and relations adopted by most urban dwellers give room for women to carry out these abusive acts on men without much notice from others. Most people prefer the private life, where only few people have access to each other's lives. For instance, the housing unit system which is usually opted for by nuclear families is believed to keep others away from noticing such practices when they occur. Therefore, the men who are faced with such experiences only keep it to themselves. This is unlike the way of life in most rural areas, where living is basically communal. Also, it was pointed out that due to the civilized and westernized cultures in the urban area, where both men and women are faced with the pressures of survival, women who are overwhelmed by these pressures easily take it out on their husbands. When this happens, depending on the individuals involved, they unleash terror on the other individual. Corroborating the opinions of majority of the respondents, some of the participants pointed out that, a good number of people live private life in the area, where everybody focuses on his or her business. In addition, due to the mix of different people who have converged in the urban area for different activities, there have been diffusion of culture and habits. Hence, different practices which were previously not common among the people have been adopted and engaged as deemed fit:

You see the way Ibadan is now, nobody knows who is who again. Everybody is just going about their own businesses, so nobody is really interested in what is happening to the other person. If you look around here now, you will see most people now stay in flats and fenced houses. If it were to be in the rural areas, we will know ourselves and ask questions when there are suspicions. But now you do not know what is happening in the next compound, even when you hear noise there, you cannot easily go there because everybody is "Alakowe" (educated people).

KII/60/Female/Bodija/March, 2020

Another participant pointed out that cases of abuse against men now happening in urban lbadan is due to women wanting to imbibe western practices where the wife also want to show dominance;
Most women now have jobs, in fact some have better jobs than their husbands such that they can afford to employ house helps and assistants. When the woman now has as much authority as the husband, she feels they are equal. She may not want to be submissive to her husband and when they have clashes, they will both want to show power and the woman can do anything to overpower the man which may harm the man.

KII/53/Male/Bodija/March, 2020

In the same vein, an interviewee opined that social and news media have projected so many behaviors into the consciousness of individuals in the urban areas. He noted that most women now want to live and behave like other people they see in different societies, all in the name of civilization. However, the cultural stereotypes of men in this part of the country has not really changed:

Once a woman is well to do more than the husband, the husband is in trouble. She will not want to follow his instructions again. In Ibadan we now have different categories of women working, once she knows that she is the catering for the house more than the husband, she will start misbehaving, because she has seen how other women behave and want to control their husband so that they can be in charge.

KII/72/Male/Oja-Oba/March, 2020

In addition, another participant added thus:

You see now with civilization; many people are opting for marriages in the registry and that is creating problem. When they have issues in the marriage, it becomes very difficult for them to separate because of the elongated procedure and cost. This is why some of them in the process harm themselves because they cannot separate easily.

KII/76/Male/Oja-Oba/March, 2020

\section{Roles of families and friends}

Majority of the respondents $71.4 \%$ were of the view that family members do not influence the abuse of men, while minority $(28.6 \%)$ believe that family members influence abuse against men. This implies that a higher percentage of the respondents believe the family members do not contribute to the abuse of men in Urban Ibadan. Also, $66.7 \%$ of the respondents which constitute the majority disagreed with the opinion that abuse against men leads to the stigmatization of family and significant others, while the minority $33.3 \%$ of the respondents are of the opinion that abuse against men leads to the stigmatization of family and significant others. The 
view of the majority may be connected to the practice of silence which is observed to be usually adopted by most male victims. This approach is adopted in order to save the image of the individual male victim involved and people or things associated to him. Hence, families and significant others alike may not experience stigmatization.

Meanwhile, majority (84.8\%) of the respondents are of the opinion that family and significant others can help to stop abuse against men, while the remaining $15.2 \%$ of the respondents disagreed that family and significant others can help to stop abuse against men. Despite the nuclear arrangements in the urban area, most household units still maintain ties to extended families and significant others, as found in most African societies. As a result of this sustained connections, conflicts and disagreements are sometimes managed and resolved by these families and significant others in the society. In addition, majority $(93.8 \%)$ of the respondents agreed that family and significant others should intervene in cases of abuse against men, while a minority $(6.2 \%)$ of the respondents disagreed that family and significant others should intervene in cases of abuse against men. This implies that a large number of the respondents still believe in the traditional role of families and significant others which promotes the spirit of brotherhood and accountability. This is regardless of the western ways of life, which is found to be gaining ground in the urban area.

The nature of most African societies, especially in Ibadan encourages individuals to maintain relationships with their families even after they are married. This continuous relationship is established as a way of strengthening the family system. This could come in the form of intervention of family members and significant others in the life experiences of individuals. This can be attributed to the communal way of life which has been sustained in many African societies. The roles played by the families and significant others vary and this could be positive or negative. In as much as families are expected to be good influence, some turn out to be bad influence and therefore further contribute to the abuse of men:

There is an adage in Yoruba that says "Bi omo oba jo sokoto, yio jo kijipa". This when translated means that a child will always take after the parent. Some parents, especially mothers contribute to their daughter abusing men when they also get married. For instance, when the child has seen her mother insulting the father or threatening the father with a knife or turning stick when she was growing up, she would begin to see those things as a way to let a man do her wish and before you know it, she would exhibit same.

KII/76/Male/Oja-Oba/March, 2020
Similarly, another participant pointed out that some women learn to abuse men through the kind of company or friends they keep. Once they are advised by their friends who also engage in the abuse of men, and the friends convince them that it is effective, they also begin to exhibit same:

If her friends advise her to do something to her husband to teach him a lesson or the friends boast of how they are the ones controlling their homes, she could also see it as a viable option to achieve her aim.

KII/50/Female/Challenge/February, 2020

However, it was also pointed out that some families and significant others have played positive roles in stemming the tide of abuse against men. Some of the participants sharing from their experiences responded thus:

When we fought and she was threatening to kill somebody to implicate me and send me to jail, I went to report to her parents. They called her and spoke to her, but she did not listen. The parents are good people, it is just the daughter that wants to be bad.

IDI/4I/Male/Oja-Oba/March, 2020

Similarly, this participant also pointed out the role played by their neighbors anytime they have their abuse episodes:

Anytime we have issues and like and we start raising our voices, sometimes our neighbors come to help us settle it and plead with her to give me back my phones and wallets

IDI/53/Male/Oja-Oba/March, 2020

In the same vein, a community leader who was a Key informant revealed that when members of the community notice abusive tendencies in families, they may try to intervene during fights or explosive arguments. However, their role is also dependent on how close they are to the parties involved in the abuse. He stated further:

I used to have a family like that in the next house to mine, whose fights became recurrent. Anytime they fight, there will be loud shouts of curses and abuses, which will attract the attention of neighbors, and of course some of us will try to mediate and settle them. However, one day during one of their fights, the woman in a bit to defend herself according to her, stabbed the husband with a broken ceramic plate. The Landlords Association had to tell the owner of the house to evict them in order prevent worse fatality

IDI/65/Male/Challenge/February, 2020 
Also, as part of the latent function of religion, some religious leaders also share their experiences in addressing issues of abuse against men. Some participants stated thus:

It takes courage for most men to come out to say they are being abused really. And sometimes, these issues are not reported at the early stage. It is when it is becoming very violent or fatal that you now see people know tell a few persons that are close to them. But because of the respect most people have for their pastors, they tell us and we intervene.

KII/60/Male/Bodija/March, 2020

Also, another participant pointed out that due to the age difference between the religious leaders and most members, they see them as elderly and more experienced to seek advice from:

Yes, you see from experience, cases like this are usually handled very carefully and not in the open, due to its nature. They know we are older than them and have more life experience. So, it may be easier for the man to share his plights with a religious leader.

KII/65/Male/Challenge/February, 2020

Speaking on the role families and significant others play in the abuse of men, some security officers had the followings to say:

There are dimensions to the intervention of the police. When the issues are still mild, maybe like disagreements and mild faceoffs, we may advise them to engage alternative dispute resolution in collaboration with their families, in order to see if the marriage can still be salvaged. However, once it involves threat to life or endanger either of the parties, we do not take it lightly, because from experience anything can happen, it might result to death or infliction of harm.

KII/36/Male/Police Inspector/March, 2020

A Peace Desk Officer at the Nigeria Security and Civil Defence Corps (NSCDC) revealed that, it is not common to have men come to report such cases.

We have a Peace and Conflict Resolution unit here in the command, which handles domestic issues like this. However, that is when the issue has not turn violent. If it gets violent and physical abuse is involved, we transfer it to the police, for investigation and prosecution.

KII/39/Male/NSCDC Inspector/March, 2020

While issues of abuse against men are treated in secrecy, the members of families of the male victim and in other instances, significant others are usually aware. More often than not when efforts have been made to resolve the issues without success, both parties are advised to separate or divorce. This is in a bid to prevent the issue from getting out of hand and guard against fatality. However, this is only explored after all other mechanisms aimed at resolving the issues have failed.

\section{Coping strategies}

Few (21.4\%) of the respondents believe abused men report to the police as a coping mechanism, while a $78.6 \%$ majority are of the opinion that abused men do not report to the police. This implies that more participants believed that men who suffer abuse do not see reporting to the security agents as a strategy to cope with the abuse they suffer. It was also revealed that $33.3 \%$ of the participants believe that abused men become more aggressive in order to cope with their abusive experience, while the majority which constitutes $66.7 \%$ of the participants believed the abused men do not use aggression as a coping mechanism. In addition, majority of the participants which represent $84.8 \%$ stated that abused men report their ordeals to family and friends as a means of coping, while a smaller $15.2 \%$ of the respondents do not believe reporting to family and friends is a part of the coping strategies used by the victims of abuse against men. Lastly, 93.8\% majority of the respondents are of the opinion that victims of abuse against men embrace silence as a coping mechanism, while a minority $6.2 \%$ of the respondents are of the opinion that victims of abuse against men do not use silence as a coping mechanism.

The participants were asked about the coping strategies adopted by the men who face abuse in the study area. It was pointed out that each individual man has his own coping mechanism against the different forms of abuse they encounter. While it was noted that there was no generic strategy of coping against abuse on men. The sensitive nature of the subject has also influenced the approach undertaken by different men in the society. The participants revealed that the type of the abuse determines the coping mechanism. This is because men respond to each form of abuse depending on the perceived gravity. Verbal and emotional abuse have been found to be, as women engage in the use of various derogatory words with the aim of causing hurt or discomfort to the man. Most men have been noted to keep their experiences within themselves. There is an observed culture of silence due to the nature of such experience, especially in a patriarchal society like Ibadan. One of the participants revealed further that: 
When she starts shouting, and raining curses on me, I just wear my clothes and go out to my shop. If I say I should beat, I will wound her, in fact she may die, because things she would be saying her things that would make me remember my loses in the business. So, I just leave the house for her.

IDI/54/Male/Oja-Oba/March, 2020

Similarly, another participant stated that he relives what could be described from his experience as emotional abuse by excusing himself from the house. He revealed that:

I know that if I go home early, she will just be nagging and singing songs that will be making me feel sad intentionally, and because of this, I almost got into depression. So, instead I stay till late in the night before coming home. When I get home, I just sleep and by the following morning I am out of the house again. If not, I will just be consumed by everything she is making me go through.

IDI/45/Male/Challenge/March, 2020

While sharing from the actions he took, when he was being abused by his former wife, another participant pointed out that he was able to cope by reaching out to his sibling. He stated thus:

After sometime, I could not keep it to myself again, I had to tell my elder brother, who further advised me to go and report to her father. Although, things did not improve, because she still continued tormenting me because I could not provide for the house, even when she knew I just lost my job. I had to later divorce her, so I can have peace.

IDI/50/Male/Bodija/March, 2020

Reacting on how he coped with the signs of the physical abuse that his wife displayed, another participant pointed thus:

Anytime, we fight like that she would throw anything she sees at me. There was a time she was threatening to stab me with scissors and it was our neighbors that had to collect it from her. That night, I did not sleep in our room because she was still boiling hot. I went with our landlord, who was also staying with us to stay in his place. IDI/48/Male/Dugbe/March, 2020

It was also revealed that seeking supernatural help as a coping strategy was not out of option, as some men engage traditional methods as a mechanism of coping with abuse against them. A participant shared thus:

In Yoruba land, when a man is facing something like that, there are some traditional procedures that they can take the man through that will prevent the woman from abusing him again.
There is what we call "Oogun Iberu", it is a charm that is made with some local leaves mixed with some other traditional things. Any man that uses it, people would be scared to do anything to him, even to talk to him, you will be shaking. Such can be prepared for any man being abused by the wife to create fear in the woman. Young people of nowadays may not be aware of it, but local people use it.

KII/74/Male/Oja-Oba/March, 2020

An examination of the opinions of the participants showed that the abused men reacted differently and engaged varied approaches to their peculiar situations. While the abuses were seemingly physical and verbal, it was however discovered that seeking supernatural ways as a coping mechanism was also seen as viable. This is especially tied to the culture of the land, where certain traditional practices have been noted as a coping mechanism against abuse against men. Therefore, men who seek such mechanisms are made to undergo certain traditional procedures and the efficacy of the traditional approach was corroborated by other participants. Also, there is a culture of secrecy with which issues of abuse against men are treated. It was observed that some of the victims did not want to give elaborate details of their ordeals at first attempts, even after some have overcome such experiences. However, the reassurance of their anonymity further helped to get them to share their experiences.

\section{Discussion of findings}

As pointed out that urban lbadan as a core Yoruba society is one that is deeply rooted in patriarchy (Shittu, Onuegbu, Ayinmoro and Fayehun 2018), the perceptions of the people about the male gender still takes a firm stand in the patriarchal and the cultural belief that men are the leaders and heads of household. This is not withstanding the diffusion of culture that is witnessed in urban lbadan, as a result of the industrialization and urbanization. The study found that women are seen as the guilty ones in many cases of abuse against men, as it is believed that a woman abusing a man cannot be justified under any circumstance. It must also be pointed out that this is the perception of some people in the study area, regardless of the western monogamous family system which seems to be patronized by most individuals in urban societies. Hence, whenever for instance a man suffer abuse as a result of attempts to marry more wives as allowed in most patriarchal societies, the man is not seen to be blamed, as such is not out of place in the African setting. This has informed the notion by the participants that men are not the cause of their abuse in the study. 
It was also discovered that abuse against men in urban lbadan also has the possibility of resulting in more cases of women abuse. This is because when men are abused, it is culturally believed that such is a taboo and this sometimes leads to episodes of continuous abuse, where the man is also motivated to carry out more fatal abuse on the woman, in order to regain authority or control in the union. Hence, due to the fact that most men have been culturally brought up to assert control, they may be pushed into making revenge moves, which perpetuates the incidence of abuse on both individuals. This is corroborated by Drijber, Reijnders and Ceelen (2013) who pointed that abuse in couples can be likened to a two-way street, where both parties alternate between being victim and perpetrator. This is however highly discouraged, as it takes the society back to the state of nature when life was solitary, nasty, brutish and short according to Thomas Hobbes. Furthermore, the study documented that people in the society are of the opinion that men should speak out when abused. This was observed to be difficult to do among men in the study area, due to the shame and embarrassment they feel, sharing their plights to others like friends and families. Supporting this observation, Machado, Matos \& Hines (2016), noted that role expectations for men and hype masculinity have made it difficult for men to see themselves as victims who need help. Hence, speaking out is perceived as one of the ways of getting help to the problem. This is also encouraged in one of the cultural sayings of the Yoruba which says "akii fi owo ton duni sabe aso", which literally means "one does not hide an ailing hand under cloth". This is said in order to motivate people not to suffer abuse in silence, as it has been commonly observed.

Different circumstances have been noted to influence abuse against men in the study area. The environmental condition of the study area is believed to be one which has provided the ease of way for men to be suffer. As an urban center, various accompanying characteristics have been noted to define living and relationships and some of these characteristics can be said to define the context of abuse against men in the study area. Most urban communities are known to live in a non-communal way, as we have in the traditional societies. This is due to the nature of the formation of the urban societies, where different people from diverse societies converge usually with the goal of achieving their industrial or business cum commerce goals. Since most people seek privacy, this informs their choices of accommodation as well as associations in the society. For instance, the preferred housing unit system in the urban area is such that would allow individuals maintain their privacy. This is why most households opt for exclusive options such as selfcontained apartments and flats. As a result, it is believed that when men face these abuses, others have little or no chance of noticing such practices when they occur. This in tandem with the findings of Asekun-Olarinmoye et al. (2019) which pointed out that abuses against men in urban areas may not be easily reported as a result of the greater level of privacy which characterize most urban societies. Therefore, the men who are faced with such experiences are left at the mercy of their abusers, as opposed to what obtains in most rural areas, where living is largely communal.

The civilized and westernized culture in the urban society has put both men and women at the risk of survival pressures in the city thereby affecting emotions and life balance. This is as a result of the frustrating conditions under which both men and women function and engage their activities. The condition of the environment of the urban center leaves many of the urban dwellers frustrated and this according to Dollard et al.'s (1939) frustrationaggression theory leads to the development of aggressive behavioral outcomes such as abuse against men. In addition, owing to the mix of different people who have converged in the urban area for different activities, there had been diffusion of culture and habits. Hence, different practices which were previously not common among the people have been adopted under the guise of civilization. This had greatly influenced the level of abuse in the rural areas and the urban areas differently, with men in the urban area more predisposed to abuse due to the aforementioned contexts.

Despite the fact that individuals do not exist in isolation, the role of kinship and social networks cant others can be said to be limited due to the sensitive nature of the subject matter. Many men find it difficult to disclose their ordeals to third parties as a result of the cultural perspective of the male gender in the society. The societal perception of men cannot be said to be greatly influenced by urbanization, as most urban societies in Africa still hold on to the patriarchal belief. The role of family and significant individuals in abuse against men can be said to be two faced. While some persons are able to influence directly, others influence can be described as an indirect input. It must be pointed out that most abuse against male victims often do not inform their families early enough, when they begin to experience abuse. For some, this is only done when the issue is becoming unbearable or life threatening for them. This is because these men see such as something that 
should not be publicized and as such, they try to keep it away from others who might have played a role or two to salvage the situation.

While it cannot be said that family members and important individuals influence the abuse, it must be pointed out that the significant others also share in the effect of abuse against men. The cultural perception of a man suffering abuse from a woman as a taboo often results in the stigmatization of the man. Such man is seen as not fit to be called a man and his opinion will not be respected in the society. He may go on to be isolated. This stigmatization is not only restricted to the man, as those associated with him such as family also face same ordeal. An individual is believed to be a representative of the family. Therefore, it is often believed that a woman that abuses a man must have come from a dysfunctional family. Also, the stigmatization of the man could as well come from within the family where he loses the respect of others and he is seen as a bad representative of the family and deemed unworthy of leadership. This can be attributed as part of the reasons why most men do not open up to family members and friends about their abuses. It is however surprising to know that families and friends at the knowledge of such abuse experience still endeavor to salvage such relationships. Efforts are often made to find resolutions to the issues which have led to the abuse of the man, while also appealing to both parties to make sure they keep their homes safe and peaceful. This is in tandem with the study of Machado, Matos \& Hines (2016) who noted that men mostly prefer the support they can get from informal sources.

This can be adduced as the reason why many of the participants only sort help from informal sources such as friends, colleagues and their close family members. The use of traditional and religious mechanisms in order to save the man from further abuse is sometimes encouraged by those who believe in such methods. This might involve some religious and traditional Yoruba practices as revealed in the study. This finding is also in tandem with the findings of Ayodele (2017) who identified that the use of spiritual means to overcome the predicaments of the male victims of abuse are also employed. It is sometimes believed that since some women make use of the spiritual means to inflict or abuse the men, such spiritual strategies should also be consulted in redeeming such man from the grip of his abuser. This also signifies the sanctity of the family system in African societies. Hence, issues noticed to cause disruption in the system are highly discouraged and frowned at. In as much as the intervention of the family and other important persons is usually aimed at preserving the family through resolutions, they also sometimes move for the dissolution of the union. This is usually the last resort in the event that all other efforts at salvaging the situation has failed. Therefore, in order to prevent fatalistic outcomes such as suicide, murder, or other life-threatening disabilities, separation or divorce may be advised.

Examining other coping strategies of abused men, it was observed that there is a general culture of silence, which is adopted by the victims in the study area. Most of the victims often find it difficult sharing their ordeals to others, and this is in order to prevent shaming and ridicule. Even when the victims suffer physical abuse and they are left with marks and injuries which may raise eyebrows or bring suspicions, they try to cover up by creating an alibi. This finding is corroborated by (Dutton and White, 2013; Adebayo, 2014) which pointed out that men are socialized to hide their challenges under private veil, including when they suffer abuses from the females. This sometimes push the victims into different acts such as alcohol, and drugs usage in order to cope with their continued stay in the relationship. However, the abuse of such substances is inevitable.

Most victims of abuse against men are not in the habit of reporting to government agencies like the police or any other organization which could have helped. Even though it has been observed that issues of abuse against men have not been given utmost attention by the different agencies in the society, the stereotyped bias where men have always been seen as the perpetrators of abuse has discouraged many, therefore they do not see such channels as part of the coping mechanisms they can trust. More often than not, many cases of abuse against men get to these agencies when there are casualties. Therefore, most victims either endure their predicaments or see it as a cross they have to bear, until they find respite. This finding is corroborated in the study of Drijber, Reijnders and Ceelen (2013) where it was also pointed out that many male victims of abuse are not motivated to talk to the police due to shame and the fear of not being taken seriously. It was also pointed out that many of these cases only get to the police when there has been severe physical assault.

\section{Conclusion}

Perspectives on abuse against men are shaped by various elements which goes beyond the individual and this influences how abuse against men had been interpreted by both the victims as well as the perpetrators of the abuse. Elements like patriarchy, culture coupled with other societal conditions like urbanization, westernization and the influence of industrialization have defined the dynamics of abuse against men in the society, with families and other 
important persons being directly and indirectly connected to the experiences of both the victims and perpetrators of abuse against men. Nevertheless, the family is also strategically involved in the mediation process of parties involved in the abuse, as parts of efforts to ensure the sustenance of familial relationships in the society. Essentially, the study concluded that victims of abuse against men have coped through strategies which are deemed selffashioned, with the absence of an organized approach to addressing the subject of abuse against men leaving victims with little or no help. Therefore, selfsustaining practices such as substance usage and other informal coping techniques like familial and religious intervention have been found to be commonly engaged by the victims. Consequently, the need for the reorientation and resocialization of members of the society on the need to see abuse as gender neutral through various media channels and initiatives is recommended. Government Agencies such as the National Orientation Agency, as well as other Non-government agencies, civil and religious associations are implored to raise awareness on the dangers of human abuse irrespective of gender, while relevant security agencies get requisite trainings on how to handle male victims of abuse, and as well cater for the protection of human rights irrespective of gender biases or appeal.

\section{References}

Adebayo, A. A 2014. "Domestic Violence against Men: Balancing the Gender

Issues in Nigeria." American Journal of Sociological Research, Vol.4(I): 14-19.

Adeniyi, O. 2018. Rape Laws in Nigeria 101. Retrieved on December 4, 2019, from http://standtoendrape.org/rape-laws-innigeria-10I/

Adeyeri, A. 2013. Nigeria: Domestic Violence - A Society Biased Against Males? Retrieved from https://www.vanguardngr.com/2013/07/domesticviolence-a-society-biased-against-males/amp/ on 26th February, 2020.

Asekun-Olarinmoye, E. O., Asekun-Olarinmoye, O. S., Adebimpe, W. O., and Omisore, A. G. 2019. "Domestic Violence against Men: Myth or Reality in the Nigerian Setting?" Texila International Journal of Public Health Vol. 7(I): 2520-3134.

Ayodele, J. O. 2017. "The Socio-cultural Causes of Male Victimization in Domestic Contexts in Lagos, Nigeria: A Qualitative Analysis.” International Journal of Criminal Justice Sciences, Vol. 12(2): 252-269.
Breuer, J., \& Elson, M. 20I7. Frustration-Aggression Theory. In P. Sturmey (Ed.), The Wiley Handbook of Violence and Aggression (pp. I-12). Chichester: Wiley Blackwell. https://doi.org// 0.1002/978 I I 1 9057574.whbva04 0

Caroletta, A. S. 2010. "Male Victims of Intimate Partner Violence in the United States: An Examination of the Review of Literature through the Critical Theoretical Perspective." International Journal of Criminal Justice Sciences, Vol. 5(I): I63-I73.

Dollard, J., Miller, N. E., Doob, L. W., Mowrer, O. H., \& Sears, R. R. 1939. Frustration and Aggression. New Haven, CT: Yale University Press.

Drijber, B. C., Reijnders, U. J. L., and Ceelen, M. 2013. "Male Victims of Domestic Violence." Journal of Family Violence, Vol. 28(2): I73-I 78.

Dutton, D. G., and White, K. R. 2013. "Male Victims of Domestic Violence." New Male Studies: An International Journal. 2(I), 5-I7.

Ellsberg, M., Henrica, J., Heise, L., Watts, C. H. \& García-Moreno, C. 2008. "Intimate Partner Violence and Women's Physical and Mental Health in the Who Multi-Country Study on Women's Health and Domestic Violence: An Observational Study." The Lancet, 37I(96/9), II65-II 72.

Johnson, M. 2008. A Typology of Domestic Violence: Intimate Terrorism, Violent Resistance, and Situational Couple Violence. Boston: Northeastern University Press.

Johnson, M. 20II. Gender and Types of Intimate Partner Violence: A Response to an Anti-feminist Literature Review. Aggression and Violent Behavior, 16(4), 289-296.

Kimmel, M. 2002. "Gender Symmetry" in Domestic Violence. Violence Against Women, 8(II), I3321363.

Krug, E. 2002. World Report on Violence and Health. Geneva: World Health Organization.

Machado, A., Matos, M., and Hines, D. 2016. "HelpSeeking and Needs of Male Victims of Intimate Partner Violence in Portugal." Psychology of Men \& Masculinity, Vol. I7(3): 255264.

Morgan, W., \& Wells, M. 2016. It's Deemed Unmanly': Men's Experiences of Intimate Partner Violence (IPV). The Journal of Forensic Psychiatry \& Psychology, 27(3), I-I5.

Morgan, W. and Wells, M. 2016. "'It's deemed unmanly': men's experiences of intimate partner violence (IPV)." The Journal of Forensic Psychiatry \& Psychology, DOI: I 0. I080/ | 4789949.20I5. I I 27986 
Namadi, M. M. 2017. "Nature and Prevalence of Domestic Violence against Men in Dala Local Government Area of Kano State, Nigeria." Journal of Social and Management Sciences, Vol. I 2(I): 10-20

Nwanna, C.R. and Kunnuji, M.O.N. 2016. Domestic Violence by Women against their intimate partners in Nigeria. African Population Studies. Vol. 30 (2). 2640-2652

Obarisiagbon, E. I. and Omage, M. I. 2019. "Emerging Trend in the Culture of Domestic Violence against Men in Southern Nigeria." International Journal of Humanities and Social Science, Vol. 9(3): 50-56

Odimegwu, C. Okemgbo, C.N. and Ayila, R. 2010. "Dynamics of gender-based violence among the Tivsof North Central Nigeria". African Population Studies. Vol. 24 (3). 238-258.
Randle, A. A. \& Graham, C. A., 20II. "A Review of the Evidence on the Effects of Intimate Partner Violence on Men." Psychology of Men \& Masculinity, I2(2), 97-III.

Shittu, L. I., Onuegbu, C. M., Ayinmoro A. D., and Fayehun, O. A. 2018. "Social Exclusion and Survival Strategies among Slum Dwellers in Ibadan, Nigeria." The National Journal of Sociology and Anthropology, Vol. 16(I): 12-30.

Tjaden, P. and Thoennes, N. 2000. "Full Report of the Prevalence, Incidence, and Consequences of Violence Against Women". National Institute of Justice, United States Department of Justice.

World Health Organization 2013. World Health Statistics 2013. Geneva, Switzerland: World Health

Organization. 